\title{
The method of the optimization of material flows for functioning of the recovery system
}

\section{Volodymyr Dachkovskyi ${ }^{A}$}

Received: April 3, 2020 | Revised: April 24, 2020 | Accepted: April 30, 2020

DOI: $10.33445 /$ sds.2020.10.2.4

\begin{abstract}
To solve the problem of timely provision of military formations (units) with the logistical means (LM), the method of optimization of material flows is proposed in the work. To implement this method, the system of the material flows management, storage and transportation of the logistical means is divided into strategic, operational and tactical levels of the hierarchy, whereby the highest management body has access to the entire management system and database and the lower one only within its responsibility. At each level of the hierarchy, an automated control system is created, which includes subsystems with normative data (set standards of storage of the logistical means, norms of variability of the corresponding nomenclature of spare parts, norms of the working time of samples of weapons and military equipment (WME) to the appropriate type of maintenance and repair, etc.). In the next stage, the accounting of records of the WME samples and the actual availability of the logistical means, which have arrived to the logistics centers of the strategic level, the distribution centers of the operational level and the warehouses of the military formations (units) is entered to the automated control system.

During the exploitation of WME samples, the information of the actual consumption of their resource is provided to the automated real-time management system. After that, the automated system compares the actual consumption of the resource of the WME samples with the established standards, which are laid down in the technical documentation and orders, regulations, directives, etc. by the Ministry of Defense and the General Staff. When the time is coming to dispatch the WME sample to the appropriate type of maintenance or repair, the automated system having the logistical means account at all levels of the hierarchy determines at which storage the logistical means data is located and paves the optimal route for their transportation to units or to the warehouses of the lower level of hierarchy.

Thus, the use of this method allows to determine the unit in which the appropriate sample of the WME will require maintenance or repair, to determine the necessary nomenclature of logistical means, to provide this unit in advance with the necessary logistical means, which will reduce the time and cost of resources to provide the logistical means to the military formations (units).
\end{abstract}

Key words: recovery, provision, weapons and military equipment, logistical means, material flows, the automated system.

\section{Introduction}

\section{Novelty of the research}

Analysis of tasks performance of military formations (units) in the operation of United forces(OUF) (anti-terrorist operation (ATO)) showed that the assurance system was not always able to cope with the amount of tasks to have been faced with [1]. It is known that the assurance system must always be developed in parallel with the development of forms and methods of conduct of hostilities (operations).

\footnotetext{
A The National Defence University of Ukraine named after Ivan Cherniakhovskyi, Kyiv, Ukraine, candidate of technical sciences, associate professor of the department of technical support, e-mail: 1903vova@ukr.net, ORCID: 0000-0003-1480-5021
} 
The new specious of WME that were allowed to exploitation in Armed Forces of Ukraine and the methods of conduct of hostilities that were imposed by illegal armed groups (IAG) made their demands for the system of the technical service, recovery of WME specious, provision of logistical means and forced to produce more modern forms and methods of providing the military formations (units).

The using of the logistic approaches in providing the military formations (units) of Armed Forces of Ukraine is intended to reduce spending's on transportation, buying of logistical means, to reduce the time spent on processing of information flows from military units (units) to governing bodies of different levels of the hierarchy on the need for the relevant nomenclature of logistical means and the most important timely transportation of the required logistical means to the designated place in the required amount at the specified time. In order to solve the problematic issues of reducing the time spent on processing information flows in the work [2] the structure of the system of logistic of Armed Forces of Ukraine and the information flows which circulating in it were proposed but the issues of distribution and accumulation of logistical means and their timely transportation remain unresolved.

The analysis of the latest researches which were dedicated to efficiency of functioning of the recovery system of WMEs, testifies [3-6], that the issues of efficiency of functioning of the technical services and recovery system of the WMEs are being considered, both in peacetime and in a special period. Namely, the effectiveness of the technical intelligence subsystem of damaged samples of MWE, their evacuation and repair is considered. It is clear that the effectiveness of functioning of the data of the components of the recovery system will depend on the timely return of repaired samples of WME in the military formations (units), which will affect the level of military formations (units) in combat. Nevertheless, it should be counted that the recovery system and its effectiveness of functioning mostly will be depending of the assurance system of logistical means. That is, considering that a damaged sample of WME was detected in a timely manner by means of reconnaissance and evacuated by means of evacuation to the place of repair, then in the absence of the necessary nomenclature of spare parts, this sample of WME will be stand in anticipation of receipt of the required nomenclature.

Nowadays, there are not the comprehensive researches which can be dedicated to dependence of the maintenance and restoration system of WME from the assurance system of logistical means. At the same time, the issues of effectiveness of the assurance system of the logistical means need to further study and to further determine the dependence of one system on the other, which makes the current study relevant.

\section{Material and methods}

\section{Analysis of recent researches and publications}

A number of works have been devoted to the study of the issues of the functioning assurance system of the logistical means, in particular in the work [7] the factors that influence on the efficiency of the logistics system functioning and the ways of improving the particular indicators of the quality of components of the subsystem of the logistics systems of the Armed Forces of Ukraine are proposed. The work [8] is aimed at studying the problem of unification of the packaging of military materials, determining the method and size of the packaging unit and the design of optimal packaging, as well as to determine the technical and methodological basis for increasing the level of packaging of military materials. So in the work [9] the optimization of the planning of the movement of transport means to facilitate efforts on doing the operation to delivery the material means is considered and proposed the algorithm of the planning of the transport flows, and in the work [10] the phases of computer-integrated design 
of flexible production systems of packing was considered. In the work [11] the analysis of the condition and factors that influence on the quality of functioning of the system of logistical provision was held. The systems of logistical provision of armed forces of the world's leading countries and Armed Forces of Ukraine were considered and in the work [12] the theoreticalmethodological and practical basements of economical mechanism of functioning of the system of logistical provision were researched. The methodic of evaluation of efficiency of logistic, which include the phases of highlighting the subsystem of logistic and the choice of the evaluational indicators of their performance, also setting limit values for estimated indicators and transferring them into score points, determining integrated assessments of functioning efficiency were presented in the literature sources [13], and in the work [14] the researches of the modern level of logistical efficiency and the issues of innovational activity were conducted and the ways of rise of the efficiency of logistic and the quality of the logistics service were analyzed. In the work [15] the characteristics of the integration process were earmarked, the phases in particular logistic sequence with development of efficiency of logistic were formed, the most precious elements of managing the integration of entities with a view to specifics of logistic chain were justified. In the work [16] the theoretical basements of logistic means of the Armed Forces of Ukraine, their main deficiencies and their influence on the situation in the areas of anti-terrorist operation were analyzed, and in the work [17] the role and functions of the warehousing and categories of logistics process efficiency, ways of placing products in storage and their impact on warehouse costs are considered and analyzed. In the work [18] the concept of warehousing logistics, which is influenced by the growth of speed of material, financial and information flows, is considered. It is analyzed that the lack of reliable and timely information on the situation in the warehouse leads to the accumulation of inventory, which leads to a decrease in volumes and increase in material costs, so the proposed system of warehouse management. In the work [19-20] the research of the role of warehouse as one of the components of logistics based on the functioning of which can be seen the effectiveness of logistics solutions. The features of organization of logistic processes in warehouses are considered and problems of warehouse efficiency are defined. Emphasis is placed on warehousing logistics methodology as an integrated part of the material flow. In the work [21] contents and ways of logistic activity are specified, methodical approaches to determining the nature and effectiveness of logistics activities are analyzed, the necessity to evaluate of evaluation the efficiency of the logistic system with the use of indicators adapted to the specifics of logistics activities is proposed. In the work [22] existing areas of logistics support for innovation processes and the level of their innovation activity were analyzed. The ways were proposed to improve the quality of logistics services. The latest innovations in the management of material flows are presented, and in the work [23] the category "flow" and their principal types of logistic flows is considered and the differences of logistic flows are generalized and also the parameters of the material flows are determined. In the work [24] the issue of development of programs of civilian military integration procurement of WME is considered

\section{Setting objectives}

On the basis of the information received about need for a particular nomenclature of logistic means, there is a need to optimize material flows to meet the needs of the recovery system of WME in a timely manner and to prevent the stand in anticipation of damaged samples of WME in repair due to the lack of a necessary repair facility of logistic means for its repair in the repair unit which will be the purpose of this article.

\section{Results and discussion}


developed in the 20th century and those that were upgraded and purchased in recent years. The high load on the assurance system of logistical means are created with a large amount of the nomenclature of WME samples, and even more so, the spare parts for their restoration, so to increase the efficiency of the functioning of the assurance system of logistical means, there is an urgent need for its optimization.

To optimize the material flows (Fig. 1) to the main server which is located at the strategic level, develop and submit the information to the electronic database on the established storage standards of logistical means in the warehouses of military units, distribution centers of the operational level, logistics centers of the strategic level, etc. That is, information is provided specifying the requirements of orders, regulations, directives, etc. by Ministry of Defense (MD) and General Staff (GS), about the volumes of stocks that should not run out in the warehouses [25].

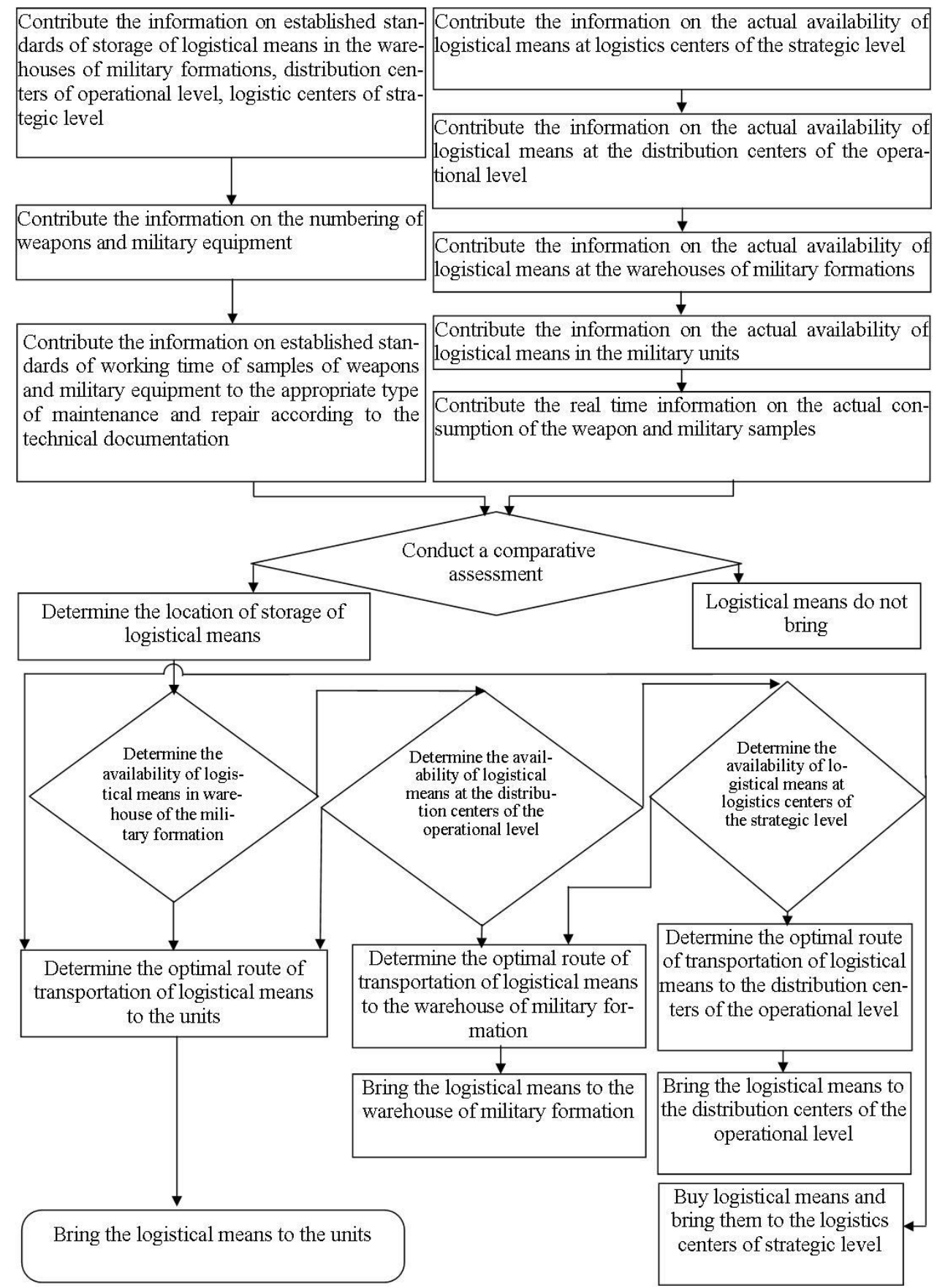

Fig. 1 Structural-logical scheme of optimization of material flows 
After that, they develop and submit to the electronic database of the main server information about the entire numerical records of the samples of the WME.

The next step of the realization of the method will be development and submission to the electronic database of the main server information on established standards for the production of WME samples to the appropriate type of maintenance and repair according to the technical documentation. That is, the norms of working time for the corresponding type of maintenance, repair or the norm of variability of the corresponding nomenclature of a part (which are specified in the orders of Ministry of Defense, General Staff, in the manufacturer's technical documentation) [26].

Then the information about the actual availability of logistical means in the strategic level logistics centers (that is, amount of the logistical means which have been bought) is entered to the main server of the electronic database. Further, the information about the actual presence of logistical means at the distribution centers of the operational level is entered to the electronic database to the operational level servers, i.e., the servers of the operational command and their equal management bodies.

In the next step, the information on the actual availability of logistical means in the warehouses of the military unit is entered to the servers of the all military formations (units) and also the information on the actual availability of logistical means in military units which are included to military formation, is entered on the same server to the block of electronic database.

Moreover, the strategic level management body can obtain information not only about the availability of logistical means and WME samples located at strategic level logistics centers, but also information about the availability of logistical means and WME samples at the operational level (in each operational command) and at the tactical level (in each military formations). But the governing body of the operational level can only obtain information on the availability of logistical means and WME samples at the distribution centers of the operational level (relevant operational command) and in the military warehouses of military formations that are directly subordinate. Accordingly, the headquarters of the military formations may receive information about the availability of logistical means and WME samples in the warehouses of the military formation and about the availability of logistical means in the military units which are the parts of the military formation [27].

An information readout device is installed to account for resource consumption for each WME sample, which transmits, in real time, information about the actual consumption of the resource of the corresponding WME sample to the military unit server. Accordingly, this information immediately receives at the server of the operational level (operational command), to which this military formation is subordinate and then the information comes from the operational level to the server of the strategic level [28].

Upon receipt of information on the servers at all levels of the hierarchy about the actual consumption of the resources of the samples, the system automatically performs a comparative assessment of the actual consumption of the resources of the WME samples with the established norms of working time of the WME samples to the appropriate type of maintenance and repair in accordance with the requirements of technical documentation (specified in the orders, MD, in the manufacturer's technical documentation). In this case, if the actual consumption of the resource by the WME samples is less than $50 \%$, then the logistical means do not bring up, and if the actual consumption of the WME samples is more than $80 \%$ then the system automatically determines the storage space of the logistical means, which are needed for the appropriate type of maintenance or repair of the WME samples.

Meanwhile, first of all, due to the fact that all the subsystems of logistical means, the numbering records of WME samples, etc. integrated between each other, the system determines the presence of logistical means in 
the warehouse of the military formation in which the appropriate WME sample requires maintenance or repair [29]. If the logistical means required for the appropriate type of maintenance or repair of the WME is located in the warehouses of the military formation, the system automatically determines the nearest warehouse and directs the optimal route of transportation the logistical means to the appropriate units. Then the transportation of the logistical means is carried out to the appropriate units.

If the logistical means required for the appropriate type of maintenance or repair is absent in the warehouse of the military formation, the system determines the presence of logistical means at the distribution centers of the operational level [30]. Meanwhile, if the logistical means required for the appropriate type of maintenance or repair of the WME samples is located at the distribution centers of the operational level, the system determines the optimal route of transportation of the logistical means to the appropriate warehouse of the military formation. Then, the transportation of the logistical means is carried out to the warehouses of the appropriate military formation. Meanwhile, the transportation of the logistical means to the military units from the distribution centers of the operational level is similar to actions which accompanied by actions of the transportation of the logistical means from the warehouses of the military formation.

If the logistical means required for the appropriate type of maintenance or repair of the WME samples is not available at the distribution centers of the operational level, the system determines the availability of logistical means at the logistics centers of strategic level. Meanwhile, if the logistical means required for the appropriate type of maintenance or repair is located at the logistics centers of strategic level, the system determines the optimal route of transportation of the logistical means to the distribution centers of the operational level. After that, the transportation of the logistical means to the distribution centers of the operational level are carried out. Moreover, the transportation of the logistical means to the units from the logistic centers of strategic level is similar to the actions, which are accompanied by the actions of the transportation of the logistical means from the warehouses of the military unit, and the transportation of the logistical means to the warehouses of the military unit, is similar to the actions which are accompanied by the actions of the transportation of the logistical means from the distribution centers of the operational level.

If the logistical means required for the appropriate type of maintenance or repair of the WME samples is not available at the logistic centers of strategic level, the system determines the optimal supplier for the procurement of the relevant logistical means, which transports the corresponding logistical means to logistics centers of strategic level.

\section{Conclusions}

Thus, the implementation of this method will provide an opportunity to have complete and objective information about the availability of the logistical means, WME samples at all levels of management and in general, to receive timely information on the need for appropriate logistical means nomenclature, to reduce the consumption of resources and time of

\section{References}

1. Vlasov I. Mechetenko M. Gannenko Yu. Analysis of the factors that influence the efficiency of functioning of the rear support transportation of the logistical means to the units and to plan timely procurement of necessary logistical means.

In the future, for the implementation of this method, it is necessary to develop a mathematical model that will allow to evaluate the quality of provision of the logistical means. 
2. Havrylyuk I.Yu. Matsko O.Y. Dachkovskyi, V.O. Conceptual bases of flow management in the logistics system of the Armed Forces of Ukraine.Modern Information Technologies in the Sphere of Security and Defence. 2019. № 1(34). p. 37-44.

3. Kryvtsun V. I. Nagachevskyi V. Ya. Baranov, A. M. Comparative analysis of existing systems of maintenance and repair of machine guns. Bulletin of mechanical engineering and transport. 2015. №1. c. 33-45.

4. Kovalenko O. A. Opportunity assessment of repair and restoration bodies for the evacuation of damaged weapons and military equipment. Modern Information Technologies in the Sphere of Security and Defence. 2016. №2 (22). p. 149-154.

5. Shyshanov M. O. Gulyaev A. V. Shevtsov M. M. Substantiation of the method of modeling the process of functioning of the system of recovery of weapons and military equipment of the grouping of troops. Weapons and military equipment. 2017. №1. c. 75-77.

6. Pavlovskyi O. V. A method of predicting volumes of tasks that will rely on repair and restoration bodies during the operations (fighting). Collection of researchers of Kharkov University of the Air Force. 2016. Iss. 2. c. 15-18.

7. Pavlovskyi I.V. Tverdokhlibov V.V. Bashkyrov O.M. Proposals to improve the logistics system of the Armed Forces of Ukraine. Weapons and military equipment, 2017. №.1(13), c. 50-54.

8. Zhang, C.H. Xie, X.P. Zhang, Z.J. Optimum design of packaging unit for military material base set. Paper Asia . 2018, vol. 1, Issue Compendium 5, p. 63-66

9. Sun, L. Zhou, X. Parmar, M. Wang, L. An improved genetic algorithm to optimize vehicle scheduling for relief efforts. International Journal of Perform ability Engineering, 2019, Vol. 15, Iss 9, p. 23562363.

10. Krestianpol, O. Computer integrated design of flexible packaging production systems. Technological Complexes, 2015, №1 (11), s. 100-110.
11. Nakonechnyi O.V. Analysis of conditions and factors that influence on the efficiency of the functioning logistics system of the state defense. Management, navigation and communication systems, 2019, №3(55). c. 48-57.

12. Gutorov O.I. Prozorova N.V. Formation of effective mechanism of functioning of logistic systems of agricultural enterprises. APK economy. 2013. №8, c. 33-39.

13. Ananko, I.M. Assessment of efficiency of functioning of logistic systems at ATP. Economy of the transport complex. 2014. № 24 c. 125-138.

14. Haidabrus, N. V. Analysis of the state of logistics services and innovation activity of Ukrainian enterprises. Businessinform. 2015. № 4 c. 123-129.

15. Skochylias, S. M. The integration process taking into account the features of the logistics chain. Economic analysis.2015. № 20. c. 295-300.

16. Nahornichevskyi, O. Conceptual principles of public administration in the field of logistics of the Armed Forces of Ukraine in the context of national security. Collection of scientific works. Public Administration Efficiency. 2015. №. 42. P. 223-229.

17. Briushkova, N.O. Hylka, B.V. Ways to increase the efficiency of warehousing of winemaking enterprises. Eastern Europe: Economy, Business and Management. 2018. vol. 1 (12) p. 48-52.

18. Krush, P.V. Mehed, Yu.V. Warehouse management system as part of the logistics strategy for condiment manufacturing companies. Economics and enterprise management. 2017. vol. 14. P. 135-139.

19. Pietukhova, O.M. Tkachuk, O. S. Improvement of organization of logistic processes at the warehouse of the enterprise. Electronic scientific edition "Effective Economics". 2018. №1. [Electronic source]: Access mode: http://www.economy.nayka.com.ua/pdf/1 _2018/6.pdf

20. Kachurovskyi, S.V. A systematic approach in the logistics of warehousing APK. Collection 
of scientific works of VNAU. 2012. №3(69). c. 93-99.

21. Mishchuk, I.P. Evaluation of the efficiency of the logistics enterprise trading system. The mechanism of regulation of the economy, 2012, № 4 c. 102-110.

22. Kosenko, V.V. Milash, L.M. Logistic support for innovation. State building. 2016. № 2. p. 1-9.

23. Vakhovska, M. Yu. Logistics flows: definitions, features, parameters [Electronic source]: Access mode: http://vlp.com.ua/files/04_25.pdf

24. Ren Xin,Tie-ying Wu, Li Yuan, Sheng Qu, Ma Li Study on the development of civil military integration equipment procurement. 5th International Conference on Machinery, Materials and Computing Technology. Advances in Engineering, 2017. vol. 126. p.1207-1211.

25. Dachkovskyi, V.O. Sampir, O.M. Algorithm of logistic protection system operation. Modern Information Technologies in the Sphere of Security and Defence. 2019. №2 (35). c. 87-92.

26. Matsko O. Y., Tereshchenko AM, Kopashynskyi S.A, Ovcharenko I.V, Dachkovskyi V.O, Yalnytskyi O.D, Openko
P.V, Yaroshenko O.V, Momot R.A., Grinchak O.V. Fundamentals of Organization of Operation and Repair of Weapons and Military Equipment, Kyiv, NUOU, 2018, 400 p.

27. Fundamentals of Logistics: Teach. manual / [Dachkovskyi, V.O. Ovcharenko I.V. Vorobiev, O.M. Yaroshenko, O.V. Melnyk, B.O.]. Kyiv : NUOU them. Ivan Chernyakhovsky, 2018. 204 p.

28. Application, IPC (2019) B60S 5/00. Method of providing units with logistical means / VA Dachkovsky, № u201909192; applications 08.08.2019.

29. Hryhorov, O.V. Anishchenko, H.O. Stryzhak, V.V. Petrenko, N.O. Stryzhak, M. H. Tsebrenko, M.V. Okun, A.O. Ziubanova, D.M. Technology of material flows of logistics systems. Kharkiv: 2018. 496 p.

30. Yatsenko, R.M. Nikolaiev, I.V. Information systems in logistics. Kharkiv: Ed. KhNEU, 2012. 232 p.

31. Tkach, M., \& Tkach, I. (2019). Analysis of the military-economic potential of some countries of the world. Journal of Scientific Papers "Social Development and Security", 9(3), 106-118. DOI:10.33445/sds.2019.9.3.8 